\title{
Cancelamento de /b,d,g/ intervocálicos no espanhol argentino de Rosário ${ }^{1}$
}

\author{
Adriana Silvia Marusso \\ Universidade Federal de Ouro Preto
}

\section{Abstract}

This paper aims at analyzing certain cases of elision of $/ b, d, g /$ in intervocalic position taking into consideration both syllabic structure and the number of syllables. The dialect under study is the Argentine Spanish of Rosario, city which belongs to the linguistic region of the Río de la Plata. Finally, the results obtained in our analysis are contrasted to John Harris' point of view (1989) in order to identify in which stage within Lexical Phonology these phenomena are placed. 


\section{INTRODUÇĀO}

7 ste trabalho pretende analisar a queda de $/ \mathrm{b}, \mathrm{d}, \mathrm{g} / \mathrm{em}$ posição intervocálica no espanhol argentino de Rosario, ${ }^{2}$ cidade que pertence à região linguística do Río de la Plata. Nessa posição, as oclusivas sonoras são sempre enfraquecidas. São realizadas foneticamente como "aproximantes puras" (cf. Martinez Celdrán, 1985, 1991) na maioria dos casos, mas podem ser canceladas em determinadas circunstâncias como veremos a seguir. T. Navarro Tomás (1959:143) também faz referência à tendência de enfraquecimento consonantal no espanhol:

Las consonantes españolas sufren numerosas e importantes modificaciones. Su articulación y su timbre aparecen menos firmes $y$ uniformes que los de las vocales. La consonante final, sobre todo, en sílaba fuerte o débil, es una articulación relativamente relajada, que obedece a toda clase de influencias por parte de los sonidos vecinos. En dicha posición, como se ha visto, las oclusivas $p, t, k$ se hacen a veces fricativas $b, \downarrow$, $g$, las sordas $s, \varnothing$, en ciertos casos, se sonorizan.

T. Navarro Tomás (1959) diz, ainda, que /b,d,g/ em determinadas circunstâncias podem cair mas que esses cancelamentos ocorrem apenas na fala vulgar, não-padrão. Porém, no dialeto aqui estudado, as variantes de $/ \mathrm{b}, \mathrm{d}, \mathrm{g} /$ em posição intervocálica podem ser canceladas em circunstâncias determinadas também na falapadrão. Portanto, os objetivos principais deste trabalho são:

a) Analisar os casos de cancelamento de $/ \mathrm{b}, \mathrm{d}, \mathrm{g} /$ em posição intervocálica e investigar sua relação com a estrutura silábica e com o número de silabas. 
b) Visualizar em que fase dentro da Fonologia Lexical se enquadram os fenômenos aqui estudados.

Para atingir os objetivos acima, o presente trabalho se desenvolveu da seguinte maneira. Primeiramente, apresentamos o cancelamento de $/ b, d, g /$ em posição intervocálica no espanhol de Rosario visando a propor uma análise que explique cada um desses casos e sua relevância dentro da estrutura da língua como um todo. Para a realização do presente estudo, contamos com um CORPUS composto por 4 horas de gravações feitas em fitas cassete e listas de 253 palavras com ocorrências de $/ \mathrm{b}, \mathrm{d}, \mathrm{g} /$ em posição intervocálica. Para a análise das fitas, realizamos medições de duração e espectrogramas dos segmentos $/ \mathrm{b}, \mathrm{d}, \mathrm{g} /$, utilizando o programa Soundscope no computador Macintosh HD 230 do Laboratório de Fonética da FALE/UFMG. A análise das listas de palavras foi realizada aplicando o bom senso e a intuição de falante nativa. Finalmente, confrontamos os resultados obtidos na nossa análise com a visão de John Harris (1989) sobre mudança sonora em progresso, procurando visualizar onde, dentro da Fonologia Lexical, enquadram-se os fenômenos aqui estudados. Na seção seguinte consideramos a análise de cancelamento de $/ \mathrm{b}, \mathrm{d}, \mathrm{g} /$ em posição intervocálica.

\section{2. $/ b, d, g />\varnothing$}

Nesta seção serão analisados casos de queda de $/ \mathrm{b}, \mathrm{d}, \mathrm{g} / \mathrm{em}$ posição intervocálica. Primeiramente, apresentamos o CORPUS utilizado, em seguida, a metodologia de trabalho e as características estudadas e, por último, a nossa análise.

\section{CORPUS:}

Para a realização do presente estudo, contamos com um CORPUS constituído por 4 horas de gravações feitas em fitas cassete e listas de 253 palavras com ocorrências de /b,d,g/ em posição intervocálica. 
As gravações foram feitas nas cidades de Rosario e Buenos Aires, Argentina, durante o mês de julho de 1993. Das 4 horas de gravação, duas foram de gravações realizadas com microfone interno, diretamente do rádio para o deck. Os falantes apresentam a pronúncia característica da região lingüística do Río de la Plata, e, talvez por se tratar de gravações radiofônicas, todos eles utilizam a fala-padrão. As outras duas horas foram de gravações realizadas com microfone externo durante conversas descontraídas na casa de amigos. Embora estas últimas tenham servido na análise auditiva, tiveram que ser dispensadas na análise digital, já que o computador registrava os ruídos externos alterando assim a onda sonora e não permitindo uma medição confiável.

Visando a atingir resultados representativos, analisamos diferentes tipos de fala:

- Parte de uma conversação telefônica radiofônica entre o repórter e um doutor. Fala ágil e empolgada, portanto rápida, sobretudo nas frases mais compridas. Embora a situação pressuponha um registro formal, não se percebem características desse tipo de registro e sim da fala informal como o "voseo" por parte do doutor ou o uso de expressões coloquiais como "no les da".

- Dois avisos publicitários radiofônicos. Pronúncia bastante artificial, com articulação exagerada e ritmo ágil próprio da linguagem publicitária, visando a dizer muito em pouco tempo.

- Panorama econômico radiofônico dado por um repórter especialista no tema. Fala relativamente rápida (210 palavras em um minuto).

- Parte de comentários radiofônicos sobre um espetáculo.

- Parte de uma conversação telefônica radiofônica entre o repórter, o Ministro da Educação e o Presidente da Federação 
Universitária Argentina. O ritmo geral da fala é pausado, respeitando-se os respectivos turnos e alternando-se, em geral, perguntas breves do repórter com respostas compridas dos entrevistados. Dentro dessas respostas, algumas frases são bem rápidas. O tom geral é formal, porém descontraído.

- Parte de um programa radiofônico noturno em que o apresentador convida os ouvintes a telefonar para a rádio.

- Parte de um diálogo radiofônico entre o repórter e umá religiosa. O ritmo geral da entrevista é bem pausado, em harmonia com o assunto, e o tom é reflexivo.

Por outro lado, construímos listas de palavras com $/ \mathrm{b}, \mathrm{d}, \mathrm{g} / \mathrm{em}$ posição intervocálica, contemplando todas as possibilidades combinatórias das vogais antecedendo e seguindo os sons em questão de acordo com os padrões silábicos possíveis da língua. Com relação ao acento, vimos casos onde $V_{1}$ e $V_{2}$, de $V_{1} \underline{b} / d / g V_{2}$, são pretônicas, casos onde $V_{1}$ é tônica e $V_{2}$ postônica, casos onde $V_{1} e$ é pretônica e $V_{2}$ tônica, casos onde $V_{1} e_{2}$ são postônicas, sendo que $/ \mathrm{b}, \mathrm{d}, \mathrm{g} /$ aparecem na penúltima ou na última sílaba. Mediante essas listas, vimos que nem todas as combinações são possiveis, já que não se encontraram exemplos para todos os casos. Especialmente, faltaram exemplos onde $V_{2}$ era $/ \mathrm{u} /$ e no caso de $/ \mathrm{g} /$ também quando $V_{2}$ era /i/. Poucos também foram os exemplos onde $V_{1}$ e $V_{2}$ são postônicas, já que as palavras proparoxítonas são pouco comuns em espanhol.

Metodologia:

Para a análise das fitas, realizamos medições de duração e espectrogramas dos segmentos $/ \mathrm{b}, \mathrm{d}, \mathrm{g} /$, utilizando o programa Soundscope no computador Macintosh HD 230 do Laboratório de Fonética da FALE/UFMG. ${ }^{3} \mathrm{~A}$ análise das listas de palavras foi realizada aplicando o bom senso e $a$ intuição de falante nativa. 
As características estudadas:

Partimos da nossa hipótese de que as variantes de $/ \mathrm{b}, \mathrm{d}, \mathrm{g} /$ intervocálicos podem ser canceladas em circunstâncias determinadas, não apenas na fala vulgar não-padrão (como afirma T. Navarro Tomás, 1959) senão, também, na fala-padrão. Primeiramente, analisamos as fitas gravadas com fala espontânea e, através da medição digital de duração e dos espectrogramas dos segmentos /b,d,g/, constatamos que existe de fato cancelamento de /b,d,g/ intervocálicos na fala-padrão. Porém, como as ocorrências registradas na fala espontânea não desvendam dados suficientes para estabelecer quais os motivos que provocam ou favorecem o cancelamento, optamos por construir listas de palavras que mostram de forma exaustiva os ambientes possíveis de ocorrência de $/ \mathrm{b}, \mathrm{d}, \mathrm{g} / \mathrm{e}$ ver em quais a queda é possível. Para isso, observamos o comportamento de $/ \mathrm{b}, \mathrm{d}, \mathrm{g} /$, considerando todas as combinações possíveis das vogais anteriores e posteriores aos sons em questão para ver se o fato de as vogais serem idênticas, diferentes, anteriores, posteriores ou glides determinava a queda. Também consideramos a tonicidade, a estrutura silábica, o tipo de palavra: funcionais, lexicais: eruditas ou não, mais ou menos freqüentes, gírias.

Em seguida, apresentaremos a análise dos casos à luz desses fatores para ver se algum ou alguns deles determinam a queda de /b,d,g/ em posição intervocálica.

A análise:

Mediante a análise no laboratório, observamos que o cancelamento de $/ \mathrm{b}, \mathrm{d}, \mathrm{g} / \mathrm{em}$ posição intervocálica acontece tanto dentro da palavra quanto em fronteira de palavra conforme ilustrado nos exemplos abaixo:

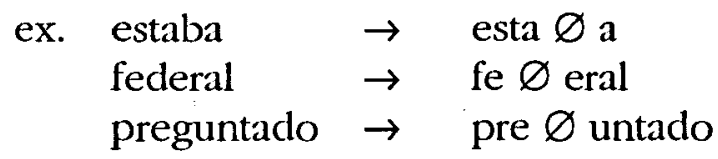




$\begin{array}{ll}\text { a \#\# volver } & \rightarrow \text { a \#\# } \varnothing \text { olver } \\ \text { perfecto \#\# doctor } & \rightarrow \text { perfecto \#\# } \varnothing \text { octor } \\ \text { te \#\# gustaría } & \rightarrow \text { te } \# \varnothing \text { ustaría }\end{array}$

Como, porém, esse fenômeno não acontece cada vez que encontra o mesmo ambiente (i.e., V(\#\#)_V), não se pode pensar que se trate de um processo fonológico, porque os processos fonológicos são recorrentes em 100\% dos casos. Assim, por exemplo, em alguns dialetos do português do Brasil, uma vogal tônica seguida por nasal é nasalizada sempre que encontra o mesmo ambiente (ex. / kama/ > [kãma]). Tal processo implica que não deveremos encontrar vogal oral tônica seguida por consoante nasal, ex. *[kama]. Isso é verdadeiro para os dialetos que requerem nasalização de vogal tônica seguida por consoante nasal. Quanto ao fenômeno de queda de oclusiva sonora no espanhol argentino, verificamos que dos 267 casos medidos, todos eles apresentando /b,d,g/ em posição intervocálica, dentro da mesma palavra ou em fronteira de palavra, houve queda de $/ \mathrm{b}, \mathrm{d}, \mathrm{g} / \mathrm{em} 28$ casos (10,48\% do total de casos), desses, 13 foram em fronteira de palavra $(9$ desses são de queda do /d/ da preposição de (ou del ), ex. uno \#\# de $\rightarrow$ uno \#\# $\varnothing$ e).

Portanto, como tal fenômeno é freqüente mas não obrigatório, concluímos que não se trata de um processo fonológico (que tem como característica a recorrência). Estudamos, então, quais os fatores que seriam significativos para que ocorra a queda através da análise das listas de palavras nas quais ocorrem $/ \mathrm{b}, \mathrm{d}, \mathrm{g} / \mathrm{em}$ posição intervocálica.

A queda de $/ b, d, g /$ apresenta restrições, porém essas não se enquadram em regras rígidas e em todos os casos vemos exemplos e contra-exemplos. Quando /b,d,g/ estão na sílaba tônica, em geral não podem ser cancelados (ex. tabaco, devoto, pidamos, hogar, agosto, etc.), mas em outros casos, na mesma situação, podem cair (ex. abajo, provincia, edema, joder, cagamos, juguemos). Como podemos ver, poderíamos interpretar o fato de que $\mathrm{V}_{1}=\mathrm{V}_{2}$ como o 
impedimento da queda de /b/ em tabaco, e é o mesmo ambiente que em abajo, sendo que nesta última o cancelamento é possível. Vários exemplos onde /b,d,g/ podem cair são sillabas tônicas com rima ramificada, ex. propincia, joder, mas também vemos exemplos como bogar, agosto com o mesmo tipo de rima onde não podem cair. Um fator que parece significativo para a aceitação da queda de $/ b, d, g /$ é o caráter familiar ou o sentido mais comum das palavras. Quanto mais erudita a palavra, menores são as chances de queda das oclusivas sonoras. Para avaliar o valor significativo dessas tendências observadas, submetemo-las ao teste de $\mathbf{X}^{\mathbf{2}}$, obtendo os seguintes resultados: ${ }^{4}$

a) em relação à tonicidade, tal teste mostra que a queda de $/ \mathrm{b}, \mathrm{d}, \mathrm{g} /$ é significativamente maior quando/b,d,g/ estão em sîlaba átona, porém, não é significativo que estejam na posição pretônica ou postônica;

b) em relação ao ambiente vocálico que rodeia $/ \mathrm{b}, \mathrm{d}, \mathrm{g} /$, não é significativo para a queda que $\mathrm{V}_{1}$ e $\mathrm{V}_{2}, \mathrm{em} \mathrm{V}_{1} \underline{\mathrm{b} / \mathrm{d} / \mathrm{g}} \mathrm{V}_{2}$, sejam idênticas. Também testamos as vogais precedentes a $/ \mathrm{b}, \mathrm{d}, \mathrm{g} / \mathrm{e}$ comprovamos que as vogais posteriores /a, o, $\mathrm{u} /$ são significativas para a queda, enquanto que as vogais que seguem /b,d,g/ não o são;

c) em relação ao tipo de palavra, utilizando os resultados obtidos na análise acústica, comprovamos que não é significativo para a queda que a palavra onde ocorrem $/ \mathrm{b}, \mathrm{d}, \mathrm{g} /$ seja funcional ou não. Por outro lado, através da análise das listas de palavras, comprovamos que o caráter comum, não erudito, das palavras é significativo para a queda de $/ \mathrm{b}, \mathrm{d}, \mathrm{g} /$;

d) também comprovamos que as percentagens sobre o total dos casos onde a queda é permitida é praticamente igual para os três segmentos, i.e., $/ \mathrm{b}, \mathrm{d}, \mathrm{g} /$ : do total de casos entre $60-70 \%$ aceitam a queda. Ou seja, o fenômeno afeta $/ \mathrm{b}, \mathrm{d}, \mathrm{g} /$ homogeneamente. 
O que é uma constante nos casos de queda de /b,d,g/ ẹm posição intervocálica, no dialeto aqui estudado, é o fato de que não há alçamento de vogais nem ditongação posterior à queda de $/ \mathrm{b}, \mathrm{d}, \mathrm{g} /$ (ex. llamado *[zamáŭ], movimiento *[moịméntol), inclusive não há redução de vogais idênticas (ex. todo *[tó]). Para o ouvido nativo, é como se a consoante estivesse subjacentemente no seu lugar, bloqueando qualquer processo de redução que trouxesse como conseqüência uma modificação na estrutura silábica e, sobretudo, no número de sílabas. É importante lembrar que o espanhol é considerado uma língua com um ritmo do tipo silábico (K.L.Pike, 1978), i.e., um tipo de ritmo onde as s1labas, tônicas ou átonas, tendem a ocorrer a intervalos regulares. Como apenas as vogais podem ser pico de sílaba em espanhol, ou seja, núcleo silábico, e sendo o espanhol uma língua com ritmo silábico, observamos uma tendência à "preservação" das vogais, enquanto que as consoantes, que não são significativas para o ritmo, sofrem modificações maiores, i.e., enfraquecimento (cf. T. Navarro Tomás, 1959).

Vejamos agora o que acontece em relação à queda, quando há mais de uma ocorrência de $/ \mathrm{b}, \mathrm{d}, \mathrm{g} /$ na mesma palavra. Visando a chegar a generalizações maiores, as palavras com mais de uma ocorrência de $/ \mathrm{b}, \mathrm{d}, \mathrm{g} /$ foram agrupadas, levando em consideração a posição de $/ b, d, g /$ em relação à sílaba tônica e à estrutura da sỉaba onde ocorrem /b,d,g/.

Grupo 1:

$\begin{array}{cccc} & \text { obedecer } & \text { seguidamente } & \text { libidin } \\ \text { 1. } & \mathrm{A} \varnothing & \mathrm{A} \varnothing \varnothing & \mathrm{A} \varnothing \\ 2 . & \varnothing \mathrm{A} & \varnothing \mathrm{A} & \varnothing \mathrm{A} \\ 3 . & \varnothing \varnothing & \varnothing \varnothing & \end{array}$

( $A=$ aproximante, $\varnothing=$ zero fônico, ${ }^{*}=$ restrição, ? = dúvida. Em todos os casos 1, 2, 3 marcam a ordem de preferência) 
Como podemos observar, nos três casos precedentes, as ocorrências de $/ \mathrm{b}, \mathrm{d}, \mathrm{g} /$ são pretônicas encontrando-se entre as seguintes seqüências vocálicas: o_e_e, e_i_a, e i_i_i. Nos três casos, aceitase a queda em qualquer uma das duas ocorrências de $/ \mathrm{b}, \mathrm{d}, \mathrm{g} /$, porém a melhor opção é aproximante na primeira ocorrência e zero na segunda. Um dos dois padrões de acentuação secundária em espanhol, i.e., o mais formal, cai alternadamente contando a partir do acento primário para a esquerda (ex. gramàticàlidád). Pode-se pensar, então, que o padrão acentual seja significativo para a primeira opção, já que a silaba imediatamente anterior ao acento é mais fraca do que a que a precede. Dos exemplos acima, obedecer e seguidamente aceitam a supressão conjunta $\mathrm{de} / \mathrm{b}, \mathrm{d}, \mathrm{g} /$; o único que não aceita é libidinoso onde /b/ e /d/ se encontram numa seqüência de três vogais idênticas i_i_i (cf. bebedero no Grupo 3 mais adiante).

Vejamos abaixo um segundo grupo de palavras em que a primeira ocorrência de $/ \mathrm{b}, \mathrm{d}, \mathrm{g} /$ está na sílaba tônica e a segunda na silaba seguinte:

Grupo 2:

cuidado podido bebida bodega investigadoseguido cagada

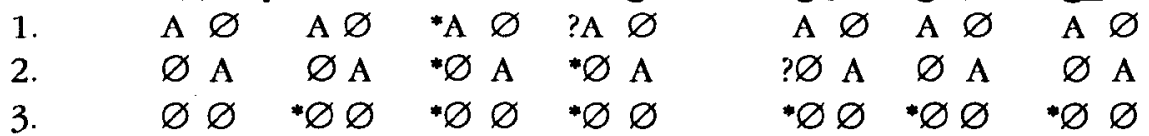

No grupo acima vemos que as restrições são maiores. Obviamente, a sílaba tônica é preferentemente mais forte do que a postônica, nessa última $/ \mathrm{b}, \mathrm{d}, \mathrm{g} /$ se reduzem com facilidade a $\varnothing$, enquanto que isso não ocorre na silaba tônica. $O$ único caso que não aceita a queda nem na posição postônica é bebida. Essa restrição é interessante pelos seguintes motivos: é uma palavra bastante comum e, através dos outros exemplos, vemos que o /d/ cai com facilidade em posição postônica, porém, se caísse nesse caso, bebi(d)a e bebía seriam homófonos, embora pertencendo a 
categorias diferentes, i.e., substantivo e verbo, respectivamente. A mesma coisa aconteceria caso caíssem as duas ocorrências juntas, já que be(b)i(d)a e veía tornar-se-iam homófonos, novamente, pertencendo a categorias diferentes, i.e., substantivo e verbo, respectivamente. Portanto, pode-se supor que /b,d,g/ não possam cair quando a queda gere formas homófonas.

Em seguida, vemos o terceiro grupo que difere do anterior pelo fato de que, na sílaba tônica, está a segunda ocorrência de $/ b, d, g /$, sendo precedida imediatamente pela primeira ocorrência:

Grupo 3:

ligadura cadavérico bebedero sudadero podadora

$\begin{array}{llllll}\text { 1. } & \varnothing \mathrm{A} & \varnothing \mathrm{A} & \varnothing \mathrm{A} & \varnothing \mathrm{A} & \varnothing \mathrm{A} \\ \text { 2. } & * \mathrm{~A} \varnothing & ? \mathrm{~A} \varnothing & \mathrm{A} \varnothing & * \mathrm{~A} \varnothing & { }^{*} \mathrm{~A} \varnothing \\ \text { 3. } & \varnothing \varnothing & { }^{\circ} \varnothing & \varnothing \varnothing & { }^{\circ} \varnothing & { }^{\circ} \varnothing\end{array}$

No grupo acima, como no segundo grupo, a silaba tônica é mais forte e não aceita a possibilidade de $/ \mathrm{b}, \mathrm{d}, \mathrm{g} /$ serem $\varnothing$. Mais uma vez o acento tende a bloquear a queda.

No quarto grupo abaixo, todas as palavras são proparoxítonas e as duas ocorrências de /b,d,g/ são postônicas:

Grupo 4:

\begin{tabular}{|c|c|c|c|c|c|}
\hline hígado & pródigo & sábado & impróvido & ávido & bóveda \\
\hline$A \varnothing$ & $\mathrm{A} \varnothing$ & $A \varnothing$ & ?A $\varnothing$ & ?A $\varnothing$ & $\varnothing \mathrm{A}$ \\
\hline$\varnothing \mathrm{A}$ & $\varnothing \mathrm{A}$ & $\varnothing \mathrm{A}$ & $? \varnothing \mathrm{A}$ & $? \varnothing \mathrm{A}$ & $\mathrm{A} \varnothing$ \\
\hline$* \varnothing \varnothing$ & $\star \varnothing \varnothing$ & $* \varnothing \varnothing$ & ${ }^{*} \varnothing \varnothing$ & ${ }^{*} \varnothing \varnothing$ & $\circ \varnothing$ \\
\hline
\end{tabular}

No grupo acima, nas palavras com final -ado, a melhor opção é aproximante na primeira ocorrência de $/ \mathrm{b}, \mathrm{d}, \mathrm{g} / \mathrm{e} \varnothing \mathrm{em}$-ado, dada a fraqueza característica desse final. Ao contrário, nos outros exemplos, vemos que a queda de qualquer uma das duas ocorrências é bastante restrita; no caso de bóveda, onde a queda é permitida, a melhor opção é a queda na primeira ocorrência, já que 
das duas sỉabas postônicas a mais fraca é a penúltima e não a última. As possibilidades de os dois segmentos de $/ \mathrm{b}, \mathrm{d}, \mathrm{g} /$ serem $\varnothing$ são nulas.

No próximo grupo, observamos que a primeira ocorrência de /b,d,g/ é pretônica e a segunda postônica:

\section{Grupo 5:}

abatatado ubicado subordinado sudestąda cogullada yugoslava

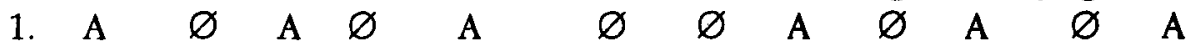

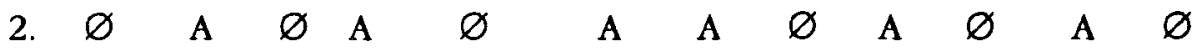

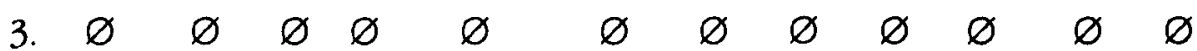

No grupo acima, observamos que as duas ocorrências de $/ \mathrm{b}, \mathrm{d}, \mathrm{g} /$ estão separadas uma da outra por, pelo menos, uma sílaba (tônica). O fato de estarem separadas e em posição átona faz com que todas as possibilidades sejam aceitas, inclusive a queda nas duas ocorrências juntas, sem se evidenciar uma ordem preferencial muito definida; porém, nas palavras com final -ado a melhor opção é aproximante na primeira ocorrência de $/ \mathrm{b}, \mathrm{d}, \mathrm{g} /$ e $\varnothing$ em -ado, dada a fraqueza característica deste final.

Nos exemplos abaixo, as duas ocorrências de $/ \mathrm{b}, \mathrm{d}, \mathrm{g} /$ também estão separadas por, pelo menos, uma sílaba (átona), mas nestes casos a segunda ocorrência está na sỉlaba tônica:

Grupo 6:

\begin{tabular}{lcccc} 
& \multicolumn{3}{c}{ rigurosidad } & \multicolumn{2}{c}{ privacidad } \\
1. & $\varnothing$ & $\mathrm{A}$ & $\varnothing$ & $\mathrm{A}$ \\
2. & $\mathrm{~A}$ & $\varnothing$ & $\mathrm{A}$ & $\varnothing$ \\
3. & $\varnothing$ & $\varnothing$ & $\varnothing$ & $\varnothing$
\end{tabular}

Se compararmos os dois últimos exemplos, vemos que são quase idênticos, já que nos dois casos as duas ocorrências de /b,d,g/ estão separadas por, pelo menos, uma sílaba (átona) e a segunda 
ocorrência está na sịaba tônica. Ambos aceitam a queda de qualquer uma das duas ocorrências, inclusive a queda na sílaba tônica é possível porque o final -dad, que sempre atrai o acento primário, é muito produtivo e por isso de algum modo previsível. Porém, o segundo caso não aceita a queda conjunta das duas ocorrências: talvez o número de sílabas que separa as duas ocorrências seja o motivo que justifique as diferenças.

Para testar essa última hipótese, em seguida, veremos outros casos semelhantes aos últimos (i.e., rigurosidad, privacidad):

Grupo 7:

\begin{tabular}{lccccc} 
a) & \multicolumn{2}{c}{ eventualidad } & & \multicolumn{2}{c}{ universalidad } \\
1. & $\varnothing$ & $\varnothing$ & $\varnothing$ & $\mathrm{A}$ \\
2. & $\mathrm{A}$ & $\varnothing$ & $\mathrm{A}$ & $\varnothing$ \\
3. & $\varnothing$ & $\varnothing$ & $\varnothing$ & $\varnothing$
\end{tabular}

b) identidad universidad diversidad modernidad

$\begin{array}{rrrrrrrrr}1 . & \varnothing & \mathrm{A} & \varnothing & \mathrm{A} & \varnothing & \mathrm{A} & \varnothing & \mathrm{A} \\ 2 . & \mathrm{A} & \varnothing & \mathrm{A} & \varnothing & \mathrm{A} & \varnothing & \mathrm{A} & \varnothing \\ 3 . & ? \varnothing & \varnothing & \varnothing & \varnothing & \varnothing & \varnothing & \varnothing & \varnothing\end{array}$

O grupo 6 difere do 7 porque, neste último, a primeira ocorrência de $/ \mathrm{b}, \mathrm{d}, \mathrm{g} /$ aparece numa sílaba que tem rima ramificada. Nos exemplos (a), as duas ocorrências de /b,d,g/ estão separadas por mais de uma sílaba, e as de (b) estão separadas por apenas uma sílaba. Os casos (a) do grupo 7 confirmam a possibilidade de queda nas duas ocorrências quando essas estão separadas por mais de uma silaba, sem que a estrutura silábica seja significativa. Porém, os exemplos em (b) mostram que alguns casos aceitam a queda das. duas ocorrências, mesmo estando separadas por apenas uma silaba: identidad (?), universidad.

Vejamos por último alguns exemplos com três ocorrências de $/ b, d, g /$. Dada a quantidade de possibilidades, torna-se difícil decidir 
com certeza a ordem preferencial, mas podemos claramente estabelecer as combinações que não são aceitas.

Grupo 8:

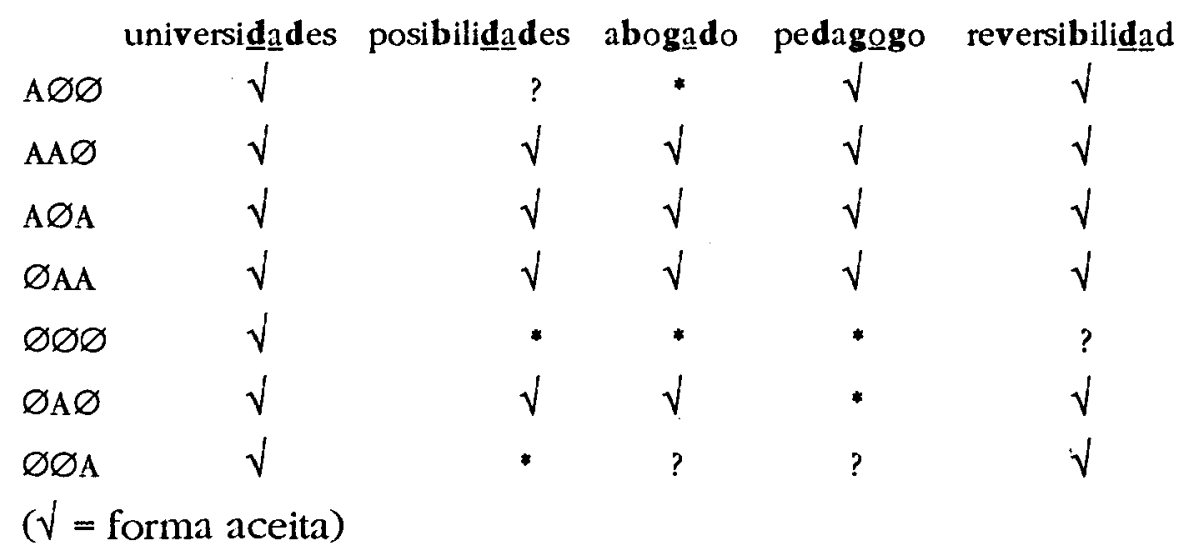

Vemos que as restrições ou dúvidas quase sempre coincidem. Em geral, estão relacionadas com a sílaba tônica e sua relação com as sílabas anterior e posterior. Por exemplo, não pode haver cancelamento nas sílabas tônica e pretônica e aproximante na postônica, que é teoricamente mais fraca do que as outras duas. Por outro lado, só universidades admite a possibilidade de cancelamento das três consoantes. Conforme foi dito anteriormente, o final -dad, que sempre atrai o acento primário é muito produtivo, por isso, de algum modo, previsível. Talvez esse seja o motivo pelo qual o /d/ possa cair com facilidade, mesmo na silaba tônica.

Resumindo, quando há duas ocorrências de /b,d,g/ na mesma palavra, a posição do acento será determinante para a possibilidade de queda. Quando as duas ocorrências são pretônicas (Grupo 1), qualquer uma das duas consoantes pode ser cancelada, porém, a preferência é que caia aquela que está em sílaba que não tem acento secundário. Por outro lado, a queda das duas ocorrências juntas é permitida caso isso não resulte numa seqüência de três vogais idênti- 
cas (ex. libidinoso "li_i_inoso, bebedero *be_e_ero). Comparando o Grupo 1 com o Grupo 4, onde as duas ocorrências também estão em sílabas átonas, embora neste último estejam em posição postônica, vemos que no Grupo 4 todas as possibilidades de queda, de modo geral, são mais restritas. Considerando os testes feitos em relação à posição pretônica ou postônica nos quais se comprovou que a posição não é significativa para a queda, é preciso procurar outra explicação para as restrições do Grupo 4. Neste grupo, todas as palavras são proparoxítonas. $O$ número de palavras proparoxítonas em espanhol é bem menor do que o de paroxítonas e oxítonas. Por outro lado, muitas daquelas são eruditas. Nos exemplos aqui estudados, sábado, bigado, e bóveda são palavras mais comuns do que pródigo, impróvido, ávido. Embora em nenhum dos seis exemplos a queda das duas ocorrências juntas de /b,d,g/ seja possível, as restrições são muito maiores para as três palavras eruditas. Portanto, conclui-se que o motivo da restrição no Grupo 4 não é a posição do acento e sim o tipo de palavra. Os grupos 2 ( $1^{a}$ ocorrência na sílaba tônica, $2^{a}$ postônica) e 3 ( $1^{a}$ ocorrência pretônica, $2^{\mathbf{a}}$ tônica) apresentam restrições similares. Em nenhum dos dois grupos é aceita a queda das duas ocorrências juntas (exceto cuidado) e é preferivel a queda na sílaba átona. Finalmente, o Grupo 5 não apresenta restrições, já que as duas ocorrências estão em posição átona ( $1^{\mathbf{a}}$ ocorrência pretônica, $2^{\mathbf{a}}$ postônica) e separadas por, pelo menos, uma sílaba (tônica). Os exemplos com três ocorrências confirman as tendências apresentadas pelos exemplos com duas.

A análise de exemplos com mais de uma ocorrência de $/ \mathrm{b}, \mathrm{d}, \mathrm{g} /$ confirmou os resultados obtidos para os casos com apenas uma. Os dois fatores que mais influenciam a possibilidade de queda são a posição com relação ao acento, i.e., a posição átona é significativa para a queda, e o tipo de palavra, i.e., a queda é mais aceita em palavras não eruditas.

As listas de palavras até aqui estudadas apresentam $/ \mathrm{b}, \mathrm{d}, \mathrm{g} /$ precedidos ou seguidos por vogais puras. Construímos outras listas 
de palavras $\operatorname{com} / \mathrm{b}, \mathrm{d}, \mathrm{g} /$ precedidas ou seguidas por ditongos. Essas listas foram estudadas separadamente com a finalidade de observar se os ditongos se comportam como as vogais puras com relação ao cancelamento de $/ \mathrm{b}, \mathrm{d}, \mathrm{g} / \mathrm{e}$, desse modo, comprovar se os ditongos em espanhol são analisáveis como seqüências de vogais: VV no esqueleto prosódico.

Com relação a $/ \mathrm{b} /$, observamos que no caso de $/ \mathrm{b} /+/ \mathrm{jo} /(\mathrm{ex}$. previo, subió, sábio), independente da vogal anterior a $/ \mathrm{b} / \mathrm{e} \mathrm{da}$ posição do acento, em todos os exemplos estudados é impossível $/ \mathrm{b} /=\varnothing$. A restrição com o ditongo crescente /je/ parece restringirse apenas à forma de gerúndio (sabiendo, babiendo), já que pode cair em outros casos, ex. proviene, tuvieron.

Com relação a $/ d /$, quando /d/ está precedido ou seguido de ditongos crescentes o cancelamento é aceito na maioria dos casos (ex. propiedad, criado, puede, estudio, mediante, radio). Contrariamente, quando $/ \mathrm{d} /$ está precedido ou seguido de ditongos decrescentes (ex. traidora, deudor, audio) o cancelamento não é aceito na maioria dos casos. Na palavra buida, o/d/ não pode cair porque resultariam em homófonos bui (d)a e buia (cf. bebida no Grupo 2).

No caso de $/ \mathrm{g} /$, independente da vogal que antecede e da posição do acento, sempre que $/ \mathrm{g} /$ está seguido por $/ \mathrm{u} /([\mathrm{u}]$ ou [w]) pode se reduzir a $\varnothing$ (ex. Augusto, legua, cigüeña). Segundo Alarcos Llorach (1976), o fonema /g/ entre uma vogal e [w] pode cair: agua [ágwa] ou [áwal, igual [igwál] ou [iwáll, lo guardo [logwárdo] ou [lowárdo].

Os exemplos com ditongos revelam vários pontos importantes. Por um lado, mostram que $/ \mathrm{b}, \mathrm{d}, \mathrm{g} /$ podem cair quando antecedidos ou seguidos por ditongos. Este fato é de suma importância para a categorização dos ditongos no esqueleto prosódico. Ou seja, o fato de $/ \mathrm{b}, \mathrm{d}, \mathrm{g} /$ poderem cair quando antecedidos ou seguidos por ditongos evidencia que os glides se comportam fonologicamente como vogais. Por outro lado, as possibilidades de queda de $/ \mathrm{b}, \mathrm{d}, \mathrm{g} /$ são bem diferentes quando estão próximos de ditongos crescentes e quando se trata dos decrescentes. As possibilidades de queda 
quando /b,d,g/ estão precedidos por ditongo crescente são de $80 \%$, e quando precedidos por ditongo decrescente, $20 \%$. Quando seguidos por ditongo crescente, as possibilidades de queda são de quase $70 \%$; quando seguidos por ditongo decrescente, as possibilidades de queda são nulas. Essa diferença tão marcada em um e outro caso pode estar revelando algum tipo de diferença entre os dois tipos de ditongos em espanhol. Essa evidência poderá ser útil em pesquisas futuras sobre as diferenças estruturais entre os dois tipos de ditongo em espanhol.

De todos os exemplos analisados, apenas num caso a queda de /b/faz duas palavras serem homófonas: cabe [káe] e cae. O interessante do caso é que cae do verbo caer pode e é comumente pronunciado [káị] enquanto que cae do verbo caber não permite o alçamento e ditongação. Isso vem confirmar nossa hipótese de que o $\mathrm{C}$ correspondente ao $/ \mathrm{b} /$ continua presente subjacentemente na representação da estrutura silábica, bloqueando qualquer processo entre as vogais.

Resumindo, a análise acústica e a das listas de palavras mostram que $/ \mathrm{b}, \mathrm{d}, \mathrm{g} /$ podem alternativamente ser cancelados em posição intervocálica, seja antes ou depois de vogais puras ou ditongos; dentro da palavra ou em fronteira de palavra; principalmente quando ocorrem em silaba átona em palavras comuns. $O$ cancelamento é aceito sempre que não resulte em formas homófonas (exceto por cabe/cae) e, no dialeto aqui estudado, não se registra alçamento de vogais, nem ditongação posterior à queda, o que mostra que /b,d,g/ continuam presentes subjacentemente, bloqueando qualquer processo de redução que traga como conseqüência uma modificação na estrutura silábica e, sobretudo, no número de sílabas, preservando assim o ritmo silábico do espanhol. A queda de fato acontece na fala-padrão preferencialmente no registro informal e ritmo ágil. Porém, como as restrições indicam, não se trata de um processo fonológico já que a regra de apagamento não se aplica recorrentemente sempre que encontra o ambiente intervocálico. 
Na seção seguinte veremos alguns aspectos teóricos relacionados com a mudança sonora em progresso, tomando como base o trabalho de John Harris (1989), Towards a lexical analysis of sound change in progress.

\section{A MUDANÇA SONORA EM PROGRESSO}

Nesta seção, situaremos historicamente a mudança sonora em progresso. Primeiramente, apresentaremos a posição Neogramática, em seguida, a Difusionista e, posteriormente, a proposta de Labov (1981). Finalmente, descreveremos rapidamente a teoria de Fonologia Lexical e sua visão da mudança sonora.

A posição tradicional neogramática é de que a mudança sonora é foneticamente gradual, livre de condicionamento morfo-sintático e lexicalmente regular. Tem-se evidência de que pelo menos algumas mudanças agem de acordo com esta visão (por ex. Labov, Yaeger \& Steiner, apud Harris, 1989:36). Tais mudanças mostram padrões de variação foneticamente contínuos sujeitos a condicionamento fonológico regular.

A posição difusionista se contrapõe à neogramática com base em estudos de mudanças que evidentemente se dão de um modo foneticamente repentino e lexicalmente irregular (cf. Wang e J. Milroy, apud Harris, 1989:36).

De acordo com Labov (1981), essa aparente contradição se resolve assumindo que temos dois tipos diferentes de mudança operando em níveis diferentes da gramática. As mudanças sonoras neogramáticas tomam a forma de modificações das regras de ajuste fonético de superfície ("low-level phonetic output rules"), enquanto que a difusão lexical ocorre num nível mais abstrato (1981:304). Labov sugere que o nível em que uma determinada mudança opera depende em grande parte do traço fonético ou fonológico em questão. Então, mudanças em regras de ajuste fonético de superfície tipicamente envolvem processos tais como anteriorização/ posteriorização de vogais ou alçamento/abaixamento de vogais e 
enfraquecimento de consoantes. A difusão lexical, ao contrário, envolve traços mais 'abstratos' tais como aqueles implicados na tensão/afrouxamento de vogais, alongamento/abreviamento de vogais, ditongação/monotongação e modificações no ponto de articulação de consoantes.

A Fonologia Lexical postula que um grupo de regras fonológicas se aplica dentro do léxico. No diagrama abaixo vemos como opera essa teoria:

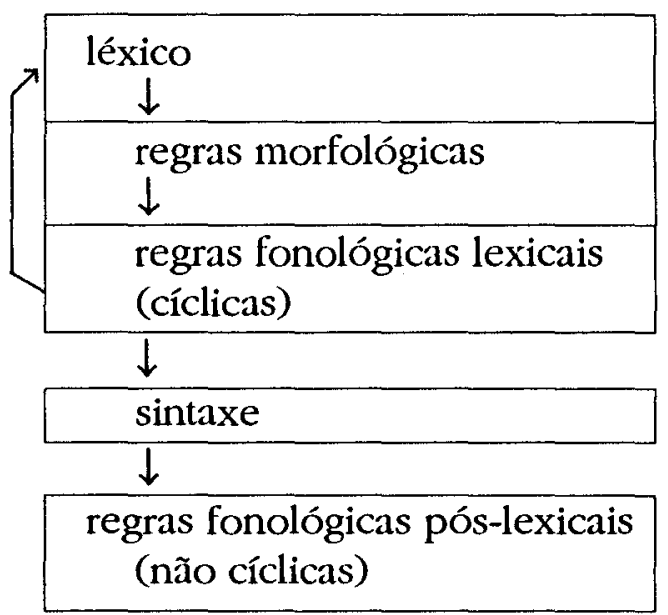

O diagrama acima indica que o output de um ciclo fonológico (lexical) é o input potencial de outra volta de aplicação de regras morfológicas e fonológicas. Quando tais processos lexicais acabam, o output está disponível para a inserção na estrutura sintática. Finalmente, um grupo de regras fonológicas pós-lexicais se aplica às palavras ou a unidades maiores.

Harris (1989) adota uma versão relativamente ortodoxa da Fonologia Lexical, como a apresentada em Kiparsky, Kaisse \& Shaw, Mohanan entre outros (apud Harris, 1989:37). As diretrizes principais dessa teoria são as seguintes. A aplicação das regras fonológicas 
envolve três módulos na gramática: o próprio componente da regra fonológica, o léxico e a camada pós-lexical (na qual as palavras se combinam na estrutura sintática). Cada regra é especificada para o domínio onde se aplica: dentro do léxico, pós-lexical ou em ambos.

O próprio léxico está composto de dois ou mais níveis ordenados (ou camadas) nos quais operam diferentes tipos de processos de formação de palavras. O número de níveis lexicais varia de língua para língua. No entanto, mais recentemente, Booij \& Rubach (apud Harris, 1989:37) propuseram que, universalmente, apenas dois níveis são motivados no léxico: um cíclico e outro póscíclico.

Cada regra fonológica que opera no léxico é especificada em relação ao nível ou níveis onde se aplica. As regras que operam na Camada 1 se aplicam ciclicamente, as que operam na Camada 2 se aplicam pós-ciclicamente (i.e., no nível da palavra). A aplicação das regras lexicais incorpora a visão de que algumas formas devem ser processadas fonologicamente durante a formação da palavra. Durante a derivação, as formas estão sujeitas ao Apagamento de Colchetes ("Bracket Erasure") que apaga os colchetes internos ao final de cada camada. Um dos efeitos dessa operação é que as regras fonológicas que operam num nível determinado não tenham acesso à estrutura morfológica interna derivada num nível anterior.

Dentre as propriedades que identificam a aplicação lexical de uma regra fonológica, Pulleyblank (apud Harris, 1989:38) resume as seguintes: ser sensível à morfologia interna da palavra, não se aplicar em fronteira de palavras e poder ter exceções lexicais. Por outro lado, a aplicação pós-lexical de regras implica insensibilidade à estrutura interna da palavra, possibilidade de aplicação em fronteira de palavra e ausência de exceções lexicais. O nível pós-lexical é nãocíclico por definição. As regras lexicais cíclicas estão sujeitas à Ciclicidade Estrita ("Strict Cyclicity"), por meio da qual estão impedidas de mudar a estrutura em ambientes não derivados (Kiparsky; Halle \& Mohanan, apud Harris, 1989:38). Outra propriedade que distingue a aplicação lexical da pós-lexical de regras 
envolve o princípio de Preservação da Estrutura ("Structure Preservation") (Kiparsky, apud Harris, 1989:38). Esse princípio determina que as regras que se aplicam no léxico não podem aumentar o inventário de segmentos presentes na estrutura subjacente. Ao contrário, as regras pós-lexicais podem aumentar livremente o inventário de segmentos durante o curso da derivação. Por exemplo, a regra que aspira as oclusivas surdas inicias em inglês não preserva a estrutura, já que introduz um traço que não é distintivo subjacentemente; aplica-se, então, pós-lexicalmente (ex. /pot/ vs. $\left[p^{\text {hot }}\right]$ ).

Conforme Kiparsky (apud Harris, 1989:38), pode ser necessário inibir a ação do princípio de Preservação da Estrutura em algum ponto durante a derivação lexical. Esse princípio, juntamente com a Ciclicidade Estrita, limita sua aplicação ao domínio cíclico, ou seja, apenas as regras da Camada 1 devem preservar a estrutura. No entanto, Harris (1989) afirma que pelo menos algumas das regras da Camada 1 não preservam a estrutura.

Há duas predições relacionadas com o papel da Preservação da Estrutura na mudança fonológica:

a) Os padrões gradientes de variação são controlados por regras que se aplicam pós-lexicalmente. Qualquer regra que opere dentro do léxico necessariamente implica distinções categóricas no sentido de que se referem a contrastes fonologicamente distintivos e, portanto, foneticamente discretos.

b) Apenas as regras pós-lexicais podem introduzir estrutura 'nova', i.e., valores de traços que não estão marcados na representação subjacente.

Dessas duas predições, apenas a primeira é confirmada pelos estudos feitos sobre mudança sonora em progresso. A visão de que padrões de variação completamente regulares e foneticamente gradientes (conforme descrito em (a)) são matéria de implementação fonética de superfície é compatível com uma análise em termos de 
regras pós-lexicais. Entretanto, em relação à predição (b), Harris (1989) apresenta evidência de dois casos em inglês, dentalização em Belfast e a tensão de vogais historicamente curtas em vários dialetos do inglês, que apontam para a existência de regras que não preservam a estrutura e que operam no léxico. Essa evidência permite uma de duas conclusões: ou se abandona o princípio de Preservação da Estrutura na fonologia ou fica ele enfraquecido de modo que defina o caso não-marcado. Ou seja, cada mudança que entra na fonologia como regra lexical mas que não preserva a estrutura, aumenta o grau de marcação dentro da gramática.

Dentro da interpretação mais rígida da Preservação da Estrutura, a lexicalização de uma regra fonológica dispararia a reestruturação repentina das representações subjacentes. Isto é, se a estrutura deve ser preservada no léxico, o novo contraste deve se tornar imediatamente distintivo subjacentemente. Entretanto, a evidência apresentada por Harris (1989) aponta para a necessidade de reconhecer uma fase 'intermediária' na qual o novo contraste entra no léxico em forma de regra lexical, sem produzir imediatamente uma reestruturação do inventário fonêmico subjacente.

A Fonologia Lexical oferece um marco coerente dentro do qual se pode seguir o desenvolvimento das mudanças sonoras na medida em que penetram profundamente na estrutura lingüística. A fase inicial de uma mudança sonora pode tomar a forma de um contraste fonético intrínseco em processo de fonologização, sendo controlado por uma regra de superfície que opera na camada pós-lexical. Ao longo do tempo, a foneticidade original da mudança pode se obscurecer por uma série de fatores. A regra pode adquirir exceções lexicais, ou pode, por pressões análogas, estar envolvida na estrutura morfológica. Qualquer um desses dois desenvolvimentos implica que a regra está em fase de transição no léxico. Então, a noção de lexicalização de regras proporciona uma explicação parcial do processo de morfologização de regras (cf. King; Hooper; Dressler; e van der Hulst, apud Harris, 1989:54). A Fonologia Lexical prevê um processo contínuo por meio do qual mudanças individuais 
podem penetrar mais profundamente dentro do sistema lingüístico. A lexicalização de uma regra fonológica representa uma fase potencial intermediária entre o começo de uma mudança como uma regra lexical e seu fim quando (e se) o contraste é fonemizado.

Nesta seção foram apresentados diferentes enfoques teóricos da mudança sonora em progresso. Em seguida, adequaremos os processos de mudança apresentados na seção anterior aos modelos teóricos abordados aqui.

\section{CONCLUSĀO}

Conforme dito na seção anterior, o que caracteriza a aplicação lexical de uma regra fonológica é que ela é sensível à morfologia interna da palavra, não se aplica em fronteira de palavras e pode ter exceções lexicais. Em seguida, consideraremos cada um desses aspectos.

Em relação à morfologia interna da palavra, a estrutura morfológica do espanhol não nos permite apresentar evidência de que nos fenômenos aqui estudados as mudanças não atingem a morfologia interna da palavra. Para provar isso precisaríamos de um exemplo do tipo [daba] (singular) e [dabs] (plural) (esses exemplos são hipotéticos) onde a regra de apagamento encontraria o ambiente para se aplicar na forma em singular mas resultaria na forma. incorreta */das/ no plural. Já que não existe nenhum caso onde $/ \mathrm{b}, \mathrm{d}, \mathrm{g} /$ apareçam em posição intervocálica dentro de um clomínio morfológico e em posição não-intervocálica em outro, como nos casos hipotéticos [daba] (singular) e ldabs/ (plural), a própria língua não apresenta evidências de que a regra de apagamento de $/ \mathrm{b}, \mathrm{d}, \mathrm{g} /$ intervocálicos não atinge a morfologia interna da palavra. Porém, existem em espanhol outros casos de cancelamento de consoantes que mostram que a regra de apagamento desses segmentos não atinge a morfologia interna da palavra. Tomemos como exemplo a palavra reloj [relóx], o / $\mathrm{x} /$ pode ser cancelado em posição final de palavra, portanto, se o domínio de aplicação da regra de cancela- 
mento fosse o morfema, teríamos a seguinte derivação incorreta para a forma plural:

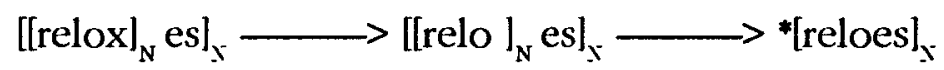

$\mathrm{Na}$ representação acima, vemos que a aplicação da regra de cancelamento dentro do morfema $[\text { relox }]_{N}$ dá como resultado a forma incorreta ${ }^{*}$ [reloes] $]_{N}$ no plural, em vez de [reloxes] $]_{-}$.

Por outro lado, nos fenômenos aqui estudados, as regras se aplicaram também em fronteira de palavras. Então, das três características da aplicação lexical de regras fonológicas, temos que deixar de lado a primeira, i.e., ser sensível à morfologia interna da palavra, já que a própria língua não apresenta evidências de que a regra de apagamento de $/ b, d, g /$ intervocálicos atinja ou não a morfologia interna da palavra. Das outras duas características, a segunda não se cumpre porque as regras se aplicaram também em fronteira de palavras, portanto, apenas se cumpre a terceira, já que os fenômenos de queda apresentam muitas exceções lexicais.

Diferentemente da aplicação lexical de regras fonológicas, a aplicação pós-lexical implica insensibilidade à estrutura interna da palavra, possibilidade de aplicação em fronteira de palavra e ausência de exceções lexicais. Conforme dito anteriormente, a estrutura morfológica do espanhol não nos permite demonstrar que as regras aplicadas nos fenômenos aqui estudados atingem ou não a estrutura interna da palavra, mas há evidências de que se aplicam também em fronteira de palavra e apresentam muitas exceções lexicais.

A evidência apresentada na seção anterior por Harris (1989) de dois casos em inglês, dentalização em Belfast e a tensão de vogais historicamente curtas em vários dialetos, que apontam para a existência de regras que não preservam a estrutura e que operam no léxico, por um lado; e a evidência apresentada neste trabalho que aponta para a aplicação de regras pós-lexicais que apresentam exceções lexicais, por outro, demonstram a necessidade de reco- 
nhecer uma fase 'intermediária' na aplicação de regras, sejam lexicais ou pós-lexicais. De acordo com Harris (1989) a Fonologia Lexical prevê um processo contínuo por meio do qual mudanças individuais podem penetrar mais profundamente dentro do sistema lingüístico. A lexicalização de uma regra fonológica representa uma fase potencial intermediária entre o começo de uma mudança como uma regra lexical e seu fim quando (e se) o contraste é fonemizado. Podese concluir, então, que os fenômenos do espanhol aqui estudado evidenciam que existem regras pós-lexicais em espanhol que estão numa fase intermediária e que portanto apresentam muitas exceções lexicais.

\section{NOTAS}

' Este artigo é parte do trabalho desenvolvido na dissertação de mestrado Fenômenos de enfraquecimento consonantal no espanbol argentino de Rosario, março/1995, onde o leitor terá informações completas. Neste artigo serão analisados apenas os casos de cancelamento de $/ \mathrm{b}, \mathrm{d}, \mathrm{g} /$ intervocálicos.

${ }^{2}$ Nomes próprios e de localidades se mantiveram na sua forma original.

${ }^{3}$ Agradeço profundamente ao Prof. César Augusto da C. Reis, Coordenador do Laboratório de Fonética, pela sua valiosa ajuda e disposição em todo momento.

4 Este é um teste qualitativo que, mediante o confronto dos dados obtidos com os esperados, permite identificar o valor significativo das tendências.

${ }^{s}$ Em outros dialetos da Argentina e da Espanha (cf. T. Navarro Tomás, 1959) existe a possibilichade de al çamento de vogais, de ditongação e de redução de vogais idênticas.

\section{BIBLIOGRAFIA}

Alarcos Llorach, E.: (1976) Fonologia Española. $4^{a}$ ed. aumentada y revisada. Ed. Gredos, Madrid, España.

Diccionario de la Lengua Española, (1986), Castell, Barcelona, España. Harris, James W.: (1983) Syllable Structure and Stress in Spanish. A Nonlinear Analysis. MIT Press, Cambridge, Mass. 
Harris, John : (1989) Towards a lexical analysis of sound change in progress. Journal of Linguistics, Vol. 25 N1, march 1989, p.35-56. Cambridge University Press.

Labov, W.: (1981) Resolving the Neogrammarian Controversy. Language, Journal of the linguistic society of America, vol. 57, N2, jun. 1981, p.267-308. Linguistic Society of America Waverly Press Inc., Baltimore, MD.

Martinez Celdrán, E.: (1985) Cantidad e intensidad en los sonidos obstruyentes del castellano: bacia una caracterización acuistica de los sonidos apraximantes. Estudios de Fonética Experimental I, p.71-129, Laboratorio de Fonética, Facultad de Filología, Universidad de Barcelona. PPU.

(1991) Sobre la naturaleza fonética de los alófonos de /b,d,g/en español $y$ sus distintas denominaciones. Verba, Anuario Galego de Filoloxía, Vol. 18, p.235-253, Separata. Universidad de Santiago de Compostela.

Pike, K.L.: (1978) Phonemics. Ann Arbor: The University of Michigan Press. 14th. ed.

Tomás Navarro, T.: (1959) Manual de Pronunciación Española. A. Fénix, Madrid. Ed. original 1918. 